\title{
Cultural Decomposition:
}

\section{How To Distinguish Figurative From Non-Figurative}

\author{
Fadil Elmenfi \\ Department of English, Faculty of Arts and Sciences \\ Omar Al-Mukhtar University \\ P.O Box 82, Derna-Libya
}

Received: 28-02-2014

doi:10.7575/aiac.ijclts.v.2n.2p.47
Accepted: 30-03- 2014

Published: 01-04-2014

URL: http://dx.doi.org/10.7575/aiac.ijclts.v.2n.2p.47

\begin{abstract}
If interpretation is so essential to the translator's work, some will argue, the entire process of translation will fall outside the realm of Semantics proper, which is the branch of linguistics most relevant to translation. The fact is that work in linguistics semantics has led to the birth of the 'decomposition' theory, alternatively 'componential' analysis, and highly useful observations have been made towards the establishment of a system of analysis capable of universal application. The objective of this paper, therefore, is to bring to light and judge the most common and preferred subjective translation methods used in the translation of cultural (informative) texts with reference to modern theories of the twentieth century which have helped to promote a systematic approach to the translation process. At this early stage, touching on them lightly will be sufficient to understand the course that this study intends to take.
\end{abstract}

Keywords: Translation and Cultural, Decomposition, Literal and Non-Literal Translation, Culture-specific words

\section{Introduction}

Translation is flourishing from day to day as no day passes without a new book being translated from English into Arabic and consequently new translation problems are raised. The fact is that with every new text in Modern Standard Arabic (MSA), the language almost invariably used in translation, new modes of thought and styles are presented which may challenge the idiomatic modes with which the Arabic reader is familiar.

Translation theories could be said to have developed in the second half of the twentieth century. In addition, translation theory provides a framework of principles, rules, and disciplines for rendering and analysing texts. Newmark (1988: 37) says "translation theory attempts to give some insight into the relation between thought, meaning, and language". The variety of translation models is a reflection of the development in modern linguistics. In this context, Gentzler (2001: 43) sees that with the application of general linguistic theory, the theory of translation has been developed. Modern linguistics attempts to provide theoretical clarifications for the nature of both language and the translation process.

The literal translation method was widely practiced in early times, particularly in Roman times. In the west, according to Bassnett (1991: 39) "the distinction between word for word and sense for sense translation was established within the Roman system."

The science of translation during that time did not exist, and therefore most translators relied on the word-for-word approach without reference to the general meaning of the sentence or the text. The literal translation method is thus based on the transfer of the core meaning of the SL units into their target language equivalents. It is very clear from this point of view that the literal method is based on a word-for-word procedure. That is to say, the translator mostly remains lexically bound to the SL vocabulary, paying little attention to contextual and cultural meaning. Wilss (1982: 87) is right in stating that "in the literal translation method, the syntactic structure of the SL text are preserved, while the semantic equivalent is preserved in the TL." From this point of view, literal translation respects the TL syntactic patterns and the collocational meanings of lexical items. To illustrate this point, consider the following example:

Let the days do what they will. د الأيام تفعل ما تثاء

In this example, a literal translation may therefore give a correct semantic rendering; hence the difficultly with this method is that it is very rare, or impossible, to find two languages that have grammatically the same structure or word order. As a matter of fact, every language has its own distinctive grammatical patterns.

Hatim \& Munday (2004: 14) consider the concept of literalness as one of exaggeratedly close adherence on the part of the translator to the lexical and syntactic properties of the ST. On the other hand, the translator using non-literal translation will aim for the indirect meaning, the analysis, not simply relying on the meanings of words but delving into the text and analysing the components of construction to concentrate on the connotative meaning of the words. This method is appropriate if applied to the translation of literary texts. As previously stated, the two methods can be classed as semantic translation, in which the dictionary has an essential role. In both models the intention is to replicate the function of the source text. According to Jeremy Munday (2001: 20) non-literal translation permits the sense or content 
of the ST to be translated. Aesthetic and stylistic considerations are again noted, and regarded among the steps towards a rudimentary classification of text types, with non-literary STs being dealt with differently from literary TTs. The former represents word-for-word translation and the latter, sense-for-sense translation. According to the previous point of view, literal translation respects the TL syntactic patterns and the collocational meaning of lexical items.

Generally, it is better to consider both models. The literal model can be used but it has to be justified. For instance, rhetorical writing is often used to make a live passage, and literal translation retains the rhetoric of the original so it is as live as the original. Using non-literal translation is justified to fill any linguistic or cultural gaps. Hatim and Munday explain that if literal translation cannot achieve its goals, we should adopt non-literal translation. The following are examples where non-literal translation could be used:

- If the general meaning of the ST would be changed when applying literal translation;

- If the meaning of the ST would not be conveyed when applying literal translation;

- If the text is structurally impossible; [i.e. structurally complex]

- If there is no corresponding expression in the TL;

- If there is a corresponding expression, but not within the same register (see Hatim and Munday 2004: $150)$.

Paying no attention to this linguistic phenomenon consequently leads some translators to focus on comparing the structure and words in the TL with those in the SL; in this case the translation process will be a process of antipodal analysis at the level of vocabulary and sentences, ignoring the fact that translation is a process of consecutive flow of ideas between the writer and the recipients of the source text translation.

\section{Combination of Literal and Non-Literal Translation}

Sometimes, the reader is able to interpret the literal meaning or figurative meaning in the source language text, without cultural conflicts being aroused, but it is often difficult to understand the implied meaning, especially the idioms, as they are lost in translation. To solve this problem, a translator should employ the translation method involving both literal translation and free translation. It will not only reproduce the literal meaning or figurative meaning so as to retain the style of the original text but also convey the implied meaning as well.

It is worth mentioning that most of the literature about translation theory has decided that it is important to mix both literal and free translation. In this respect, in the book Theories of Translation: an anthology of essays from Dryden to Derrida, Dryden (1992:26) selected a style to mix them; he said "I thought fit to steer betwixt the two extremes of paraphrase and literal translation; to keep as near my author as I could, without losing all his graces".

Eugene Nida (1964), translator of the Bible, refused to divide translation into literal and free translations. He believed that there are more degrees than those mentioned. Nida (1964: 156-158) sees that differences in types of translation are due to two main factors that form the nature of a text that should be conveyed through languages; main goal of original text; and audience (readers) of translated text. The basic difference is defining the priority of the text. Poetry, for example, is interested greatly in form but that does not mean it neglects meaning, while instruction texts are more interested in content and should be translated in aesthetic form. Finally, translation should take into account its audience as that defines the level of language because readers differ in their abilities to read translated material and also their fields of interest differ.

Nida concluded that there are two general trends of translation, not two types of translation; the first is concerned with formal equivalence that concentrates on form and meaning; this type is the nearest to what Schleiermacher calls foreignization in his seminal lecture On the Different Methods of Translation (1813). Nida advises the use of dynamic equivalence that aims at producing a matching text with all of the details and linguistic characteristics of the target language; this is what Schleiermacher call naturalization or free translation. Moreover, Nida suggests four conditions of a translated text:

- A text should have a clear meaning.

- A text should transmit the characteristics of the original text.

- A text should have a simple style.

- A text should convey the same feeling and message as the original text, (Nida 1964: 155-159).

To arouse the curiosity of a reader due to strangeness of text as a result of literal translation, Schleiermacher says that keeping the strange characteristics of the original text requires good translation skills in order to keep those characteristics as authentic as possible without neglecting the target characteristics completely (see On the Different Methods of Translation 1813).

To conclude, we may assume that, by literal translation, only the reader will find it hard to figure out the implicated meaning, despite the fact that he/she is able to understand the literal meaning or figurative meaning in the source language text without any sort of cultural conflicts. In this respect, Fadil Elmenfi (2012:229) states that in order to make the implicated meaning revealed with the literal and figurative meaning retained in the translated text, the combination of literal and free translation is to be applied in translating such texts. 


\section{SL vs. TL Orientation}

Translation is culturally perceived to be as equally concerned with two (or more) cultures as with two (or more) languages. This requires the translator not only to be bilingual but also bicultural, if not multicultural, to convey an intact SL message. Thus, translation as Toury (1980: 200) asserts is "a kind of activity which involves at least two languages and two cultural traditions".

It is very controversial to make a judgement on which one of them is right (the literal or non-literal) translation, as both of them have logical reasons to be used. However, the same opposition has recently changed into a source cultural text vs. a target cultural text opposition. The translation process is not just a conversion or transference of the word or symbol from the SL to the TL, but it depends heavily on the interpreter.

Thus, we cannot disagree with Elmallah (2008: 38) who says that linguistically, translation is more SL-oriented, but culturally translation is more TL-oriented, since one of the most effective translation approaches suggests that in order to help readers acquire a translated work easily, they should be allowed to feel that the target text is familiar to them by applying elements of their own culture to the translated work to make the target text fit in with the dominant culture.

The above discussion of whether a translated text should be SL-oriented or TL-oriented, shows that the translator should produce as close a natural translation as possible which binds the two approaches to each other. Thus, it may be highly desirable that the translation would be TL-oriented in the sense of form, but in terms of the content, it might be preferable to produce a SL-oriented translation. According to Nida (1964:165), a formal-equivalence translation is basically source-oriented: it is designed to reveal as much as possible of the form and content of the original message. Another point is that the SL-orientation approach leads to adequate translation, whereas a TL-orientation approach leads to accepted translation in the light of Toury's terms adequacy versus acceptability. However, for Chesterman (1997:171), foreignizing strategy gives priority to the target text, whereas a naturalized strategy gives precedence to the source text.

\section{Word Connotation}

Words do not only have a lexical meaning; it has long been an accepted fact that, in addition to a primary meaning, words have secondary and figurative meanings. That is to say, words can carry metaphorical meaning as well as the basic meaning of the word.

The translator should emphasise exact meaning in the TT. In this regard, connotational meaning may be described as associative meaning referring to the sense of an expression in a particular context, especially when that word is used in combination with other words in a text. To illustrate this, consider the following expression that carries a deep connotative meaning depending on the context in which it occurs. The expression "يا خبر أبيض"Belongs to the Egyptian colloquial dialect used infonnally, particularly by uneducated classes, corresponding to the English "goodness me!." This expression creates meanings that the words do not have in isolation, and even meanings that are not wholly predictable from the senses of the words combined. Thus the two words "خبر - أبيض"together represent a culturally specific meaning which connotes an attitude of negative or positive responses where people may actually have sense of surprise or shock. However, rendering the ST expression "يا خبر أبيض"into the TT as "goodness me" successfully maintains the sense intended in the original, which is surprise and shock. In my view, both expressions may be considered as semantically equivalent on the cultural level, belonging to the register of informal expressions, and hence are suitable for dialogues in both the ST and IT.

Moreover, consider the Arabic expressions: "ثاهد عيان - هذه عين ـ يعيني راسه - عيون الماء"Each of these expressions and collocations containing the word "عين عين" give different meanings. Evil eye, or in Arabic allows for more than one interpretation. For example. it can indicate a bad situation to one person whereas in another context it has a very different meaning "ثاهد عيان"or "eye witness". Moreover, the word "العين"can be used with different metaphorical senses. For example, in the following hadith (saying by the Prophet):

$$
\text { عينان لا تمسها النار عين بكت من خشية الله و عين باتت تحرس في سبيل الله. }
$$

Two eyes cannot be touched by fire, one eye which cried from fear of God, and one eye spent the night watching over for the sake of God.

"أحمل الزمن المحترق في "Another example is a line from the poet Nizar QabanI discussed in Dickins et aI., which reads "عيني. This has been translated into English by Rolph as "1 carry this scorched era in my eye". Here the English term "scorched" is acceptable in this context, mainly because the phrase "scorched era" echoes the military phrase "scorched earth". Accordingly, any given linguistic form in the SL may have other connotations besides its information content. These connotations may have to do with attitudes or emotions. Since such meanings are usually culturally conditioned, the meaning may be lost in the translation process if the translator is not aware of the added non-referential meaning.

"لم يكن وصلك إلا حلما في الكرى أو خلسة الحختلس" : This may be illustrated by Monroe's translated verse of Ibn-al-khatTb's verse rendered into English as "Union with you is now but a dream during drowsiness or the deceit perpetrated by a deceiver". Here, the Arabic term "الكرى"In this context means a deep sleep or "slumber". That is to say. it refers to a state of deep sleep, rather than a nap or light sleep "نعاس". Monroe's translation attempts to give the term "drowsiness" as a functional equivalence, ignoring the metaphorical meaning of this term. Along similar lines, Monroe also gives unsatisfactory renditions for "الدار" as abode and "تقلى" as show pity", neither of which conveys the real sense of the وهذه الدار لا تبقى " : original version. Monroe offers: "and this abode that will show pity for no man", for the Arabic verse " ملى أحد". 
From a semantic point of view, it is true that the ST lexical item "الدارlin the Arabic verse means "abode" as Monroe puts it. However, according to the poetic contextual meaning. the word carries other connotational and cultural meanings in addition to its basic sense. It can also refer to the concept of life according to Arabic and Islamic culture. Moreover, the use of the Arabic demonstrative pronoun "هذهاة"emphasizes present life, which in Arabic means "الدنيا. Thus, it is certainly true that words have other affective connotations in addition to their informative semantic content and value. Expressions, proverbs and so on carry various informative connotations that should not be ignored by translators. For this reason, translators who are used to dealing with the translation of poetic language, such as using word connotation, may sometimes forget the influence of context on the meaning of words. The same word(s) will have different meanings depending on:

1. The other words in the text in which it occurs.

2. The way it is used in the text.

3. The cultural and situational background of the context outside of the text itself.

In addition to these types of contextual influence, meaning is determined by word connotation and its collocation with other words. Scholars such as Ullman $(1962,1979)$, Lyons (1977) and Palmer (1981) have discussed this. However, Ullman (1979:49) points out that: "modem linguists have not only placed greater emphasis on context but have considerably broadened its scope and have also probed more deeply into its influence on word meaning."

The challenge for the translator, then, is twofold. First, the figurative meaning of lexical items poses a great challenge for translators of poetic texts; hence, a translator must recognize when words in the SL are being used in a secondary sense in order to produce a reasonable translation. Second, when a word in the TL is being used in its secondary meaning, care must be taken to build in the adequate context to guarantee correct meaning, since secondary meanings are dependent on context.

\section{Meaning and Culture}

Translation as a means of communication normally communicates the intended meaning of the original message (SL) to its counterpart (TL) culture in a different language and to a different audience. While linguistic theories provide the basis for the translation process, they also offer an analysis of the linguistic form of SL units (word, sentence or a text) without much attention being paid to the SL author, his/her social /cultural background, status, textual matters, consideration of its culture, or the circumstance of the communication.

A theory of translation, however, includes more than the text itself. Larson (1984: 430) states that the meaning of a word or a sentence depends not only on its place in the text but also on other factors and matters outside the text. For example cultural facts and factors are also relevant to the interpretation of SL word meaning. In this regard, Larson notes that: meaning of this kind needs to be conveyed with the conditions of a culture and its audience. Larson (Ibid : 431) He gives a clear cut picture when he states that: "each society will interpret a message in terms of its own culture. The receptor audience will decode the translation in terms of its own culture and experience, not in terms of the culture and experience of the author and audience of the original.

\subsection{Culture-Specific Words and Translation Broblem}

This section demonstrates why an understanding of ST culturally-specific words is needed. Cultural words and issues display various connotational semantics that need to be considered by the translator. Hammuda (1998: 78) states that translations not only give us access to texts that would otherwise remain inaccessible to our curious minds, but also help us to develop a certain view of the culture that produced it.

English and Arabic have vastly different characteristics both linguistically and culturally. Linguistically, the two languages belong to very different language families: English is an Indo-European language while Arabic is a Semitic one. Consequently, there are no complete correspondences between the languages.

In Arabic culture, there are various words that carry with them the atmosphere and rhythm of a cultura/historical and aesthetic tradition. Specific cultural views lead to difficulty in translating SL cultural words in bridging the gaps to facilitate an understanding of culture, where communication raises awareness of the role of culture in constructing, perceiving and translating reality.

The translation is viewed here as essentially an aspect of a larger domain, namely, that of communication across cultures. Hence, the subject of culture is taken into consideration in the translation process and has been discussed widely by a variety of translation scholars. Among these, Baker (1992), Bassnett (1980: 190), Lefevere (1975-92), Hatim and Mason (1990-1997), Holmes (1972), Nida (1964-2002), Venuti (2001-003), Hawthorn (2000), and Newmark (1981-88) all discussed the influence of culture during the translation process, paying particular attention to cultural aspects, words, facts and factors, facilitating communication and understanding between persons or groups who differ with respect to language and culture. Accordingly, the task of translation needs to proceed cautiously given the cultural differences between SL and TL establishing and balancing the communication between the two cultures; the translator must be to a certain extent bicultural.

In Arabic culture we find words and expressions that convey the cultural, historical and aesthetic background of the Middle East; therefore, one should pay particular attention to all aspects of culture expressed by words and features embedded in ST cultural settings. Such words and expressions represent the cultural sphere of the ST; hence they show different cultural meanings. Consider for example the following expressions: 
حتى المحاريب تبكي وهي جامدة ـ الغيث النافع ـ ليل قر ـ ليل بارد ـ قرة العين.

Such words and expressions are used with particular meanings in various texts, and hence can cause problems affecting the translation process. Translators have to be careful when selecting appropriate equivalents for Arabic words, particularly metaphorical words and expressions. Cruse (1986: 42) notes metaphorical words and expressions in languages are used sufficiently and frequent $y$ with particular meanings.

We now examine some examples of words/expressions $\mathrm{m}$ order to reflect on some important cultural differences between the two languages. Two cultures involved in a translation may have different environmental backgrounds with regard to elements such as climate, flora and fauna. The environmental features of the Middle East and the UK are used as an example.

Both the Arabic and English languages reflect differences when referring to ecology. While the Middle East has a hot and very dry climate, the UK's climate is cooler and wetter. A translator of Arabic/English texts may come across problematic aspects of ecological expressions; some words have different connotations in the other's language. For example, Arabic expressions associated with coldness express favourable connotations: "قرة العين"literally means coolness of the eye. On the other hand, the equivalent ecological English expressions that have favourable connotations are usually associated with warmth, for example, warmth of the eye. The English expression: "he was given a warm welcome" is another example that has a positive connotation. In Arabic, some expressions associated with warmth carry negative connotations. For example, "سخنت عينالك literally means may your eyes be hot, that is harm is wished to you. This can be contrasted with the Arabic expression "ابنتي قرة عيني" "which literally means "my daughter is the coldness of my eye", conveys a sense of gladness and delight towards someone who is loved.

However, the Arabic term "العين"carries different meanings in different contexts. In the above example, it gives the sense of "coolness" which is a desirable property in a hot climate where heat is associated with unpleasantness, and therefore is used in the sense of well wishing. It is also used in religious texts associated with some Qur'anic verses قرة" عيني لي ولك" It is, however, interesting to mention here how warmth is used metaphorically in Arabic. This idea is understandable now that we have understood that hotness is frequently used in Arabic in a negative sense. Furthermore, in modem dialects of some Arab countries, the expression "عارة"literally "his eye is so hot" means that this person is dissatisfied with his/her fortune and wants what other people have; it expresses envy.

The second example is the Arabic expression "الغيث النافع"which literally means rainwater or rain clouds. The Arabic term الغيث اs used by Arab poets in many situations to denote goodness and prosperity. It is used by the Arab mediaeval poet Ibn al-KhatTh and is translated into English by Monroe as follows:

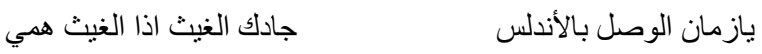

May the rain cloud be bountiful to you when the rain

cloud pours, O time of love union in al-Andalus

Monroe has clearly inserted the English term "bountiful" to refer to the Arabic term "غيث"which implies goodness and prosperity. This is one instance where translators need to consider cultural aspects and issues in order to provide clear and faithful renditions. It is used by most Muslim people after their prayers in the form of supplication "دعاءع a request, a plea for water, by means of asking Allah to provide rain for prosperous farming and bountiful pastures to feed their cattle': أللهم ارزقني غيثاً نافعاً.

The third example is in the use of "محراب" in the singular, "محاريب in literally means the place of the imam at prayer time. The Arabic term "محر اب"is used by poets to show a culturally specific aspect. Therefore translators need to consider the particular use of the term "محر اب"when translating specific ST verses.

Wierzbicka (1997: 5-6) notes that: words with a specific cultural nature and meanings are to be considered as conceptual tools that reflect a particular ST knowledge of past tradition given to a living characteristic of a society and its experience. Thus "حتى المحاريب تبكي و هي :stands as a culturally specific item used by al-RundI in verse no.24" جامدةto show the real condition of the Muslims in being weak, crushed and collapsed. This verse is rendered into English by Monroe as: "Even the mihrabs weep though they are solid". In this version, it appears that the English language does not have an equivalent word that corresponds to the Arabic term "الدحاريب". This example shows how cultural differences can stand as a barrier and cause difficulties to literary communication. Monroe resorted to providing a transliteration for this term, aiming to preserve the ST cultural aspect of Arabic culture. This leads one to emphasise that the process of transmitting cultural elements is a complicated task. Culture is thus a complex collection of experiences. It includes history, social structure and everyday usage. However, most importantly, what applies to one specific culture may not to others, particularly for words that have special cultural aspects reflecting SL cultural features.

Thus, the absence of such cultural terms in English may affect the global understanding of SL cultural concepts, tradition, life, and beliefs. As an example of these issues, the Arabic simile image "literally means "cold as marble" giving the sense of "coolness" in the hot climates of the most Arab countries. In English speaking society, simile images are fundamental parts of the texture of the spoken English language. An example of this is the English expression "mad as hell" as an equivalent to the Arabic "غاضب جد", showing one's anger and distress. Abu-Ssaydeh (2006:31) notes that to "native speakers of English, similes are not merely stylistic ornaments; they are deeply embedded in the texture of the language. 
On the other hand rendering the Arabic expression "can be translated into English as "touch wood" which clearly refers to a state of affairs in both cultures in which the expression conveys a particular sense of being lucky. Thus, the English equivalent "touch wood" is a literal rendering of its counterpart, expressing the same denotation and connotation. This is one of the few instances in which Arabic and English share a cultural expression with approximately the same nuances. For the translation of such original expressions, Newmark (1988: 112) recommends a literal rendering preserving their referential and aesthetic character, sense and image.

In the final example, certain animals may be familiar in one culture but not in the other, which can lead to a translational gap. Niiqa "she-camel" for example, is familiar in the Arab environment and hence is commonly mentioned in Arabic poetry. Some cultural differences might be non conventional in terms of the topics to which they refer. For example, in the naqa sections in some odes no common ground for translating them has been found yet. This is because scholars have only become interested in cultural dimensions in the last three decades as translation has developed and moved towards culturally oriented approaches.

With the above examples in mind, cultural issues, expressions, terms and matters of the ST can pose various problems to translators in conveying the intended meaning of the ST message. Accordingly, translators should be familiar with such issues in order to understand the literary content as well as the cultural meaning of the ST. Furthermore. translators also need a solid background in the cultures they are working with, particularly the literary sphere of old notions such as the Greek, Roman, English and Arab worlds. Such knowledge helps translators to decide on the right and proper methods, strategies and techniques for translating literary texts from culture to culture and therefore forms a useful perspective on and guide to cultural information for the translator in understanding the ST message that is embedded in the cognitive environment of a particular culture.

\section{Conclusion}

This paper has looked at the crucial difficulties and revealed differing opinion of modem scholars with regard to the translatability from culture to culture. In doing so, the paper has focused on a discussion of both linguistic and cultural issues that translators encounter as they deal with different terms, idioms and expressions. Specific attention has been given to word meaning, word connotation and word collocation.

\section{References}

Baker, M. (1992) In other Words: a Coursebook on Translation, London, Routledge.

Bassnett, S. (2002) Translation Studies (3rd version), London: Routledge.

Bassnett, S. (1991) Translation Studies (revised edition). London and New York: Routledge.

Chesterman, A. (1997) Memes of Translation: The Spread of Ideas in Translation Theory. Amsterdam and Philadelphia: John Benjamins.

Elmenfi, F. ( 2012) Strategies for Translating Cultural Arabic Informative Texts into English: A Foreignizing Approach, Unpublished PhD thesis, Durham: University of Durham.

El Mallah, F. (2007) Cross-cultural/Linguistic translation of the figurative language of The Quran. Unpublished PhD thesis. University of Edinburgh, Edinburgh.

Gentzler, E. (2001) Contemporary Translation Theories, Clevedon: Multilingual Matters.

Hatim, B. \& Munday, J. (2004) Translation: an Advanced Resource book, London and New York: Routledge.

Hammuda, A. المر ايا المحدبة: من البنيوية إلى التفكيكية (1998) [Convex Mirrors: from Structuralism to Deconstruction] Kuwait: The National Council for Culture, Arts and Literature.

Hawthorn, J. (2000) A Glossary of Contemporary Literary Theory, London: Arnold.

Larson, M. (1984). Meaning-based translation:A guide to cross-language equivalence (2 ${ }^{\text {nd }}$ ed). Lanham, New York \& London:University Press of America.

Lefevere, Andre (1992) Translating Rewriting and the Manipulation of Literary Fame, London and New York: Routledge.

Munday, J. (2001) Introducing Translation Studies: Theories and Applications, London: Routledge.

Newmark, P. (1988) A Textbook of Translation, New York: Prentice Hall.

Nida, E. (1964) Toward a Science of Translating: with Special Reference to Principles and Procedures Involved in Bible Translating, Leiden: E.J. Brill.

Schulte, R. and Biguenet, J. (1992) Theories of Translation: an anthology of essays from Dryden to Derrida, Chicago; London: University of Chicago Press.

Schleiermacher, F. (2000) "On the Different Methods of Translation", in Venuti, L (ed.) The Translation Studies Reader, London: Routledge.

Toury, G. (1980) In Search of a Theory of Translation, Tel Aviv: Porter Institute for Poetics and Semiotics.

Venuti, L. (2000) The Translation Studies Reader, London and New York: Routledge.

Wilss, W. (1982) The Science of Translation: Problems and Methods, Bingen: Narr. 